\title{
Alcohol-Related Dementia and Neurocognitive Impairment: A Review Study
}

\author{
Ankur Sachdeva, ${ }^{1,}{ }^{*}$ Mina Chandra, ${ }^{2}$ Mona Choudhary, ${ }^{2}$ Prabhoo Dayal, ${ }^{3}$ and Kuljeet Singh Anand ${ }^{4}$ \\ ${ }^{1}$ Department of Psychiatry, ESIC Medical College and Hospital, Maharishi Dayanand University, Haryana, India \\ ${ }^{2}$ Department of Psychiatry and Drug De-addiction, Post Graduate Institute of Medical Education and Research (PGIMER), Dr Ram Manohar Lohia Hospital, Guru Gobind \\ Singh Indraprastha University, New Delhi, India \\ ${ }^{3}$ National Drug Dependence Treatment Centre (WHO Collaborating Centre), All India Institute of Medical Sciences (AIIMS), New Delhi, India \\ ${ }^{4}$ Department of Neurology, Post Graduate Institute of Medical Education and Research (PGIMER), Dr Ram Manohar Lohia Hospital, Guru Gobind Singh Indraprastha \\ University, New Delhi, India \\ "Corresponding author: Ankur Sachdeva, Department of Psychiatry, ESIC Medical College and Hospital, Maharishi Dayanand University, Haryana, India. Tel: +91-1126593236; \\ +91-9899528355, Fax: +91-1292413032, E-mail: drankur.rml@gmail.com
}

Received 2015 March 07; Revised 2015 June 01; Accepted 2015 July 05.

\begin{abstract}
Context: Alcohol consumption has escalated rapidly in many countries over the past decade. Evidence suggests a correlation between alcohol use and cognitive decline. We have systematically reviewed the concept and controversies, epidemiology, nosology, neuropathology and neurobiology, neuropsychology and management updates of alcohol-related dementia (ARD) in this paper. Evidence Acquisition: We retrieved papers for this review by searching the PubMed database for terms "alcohol and dementia", "alcohol and cognitive impairment", and "alcohol and wernicke-korsakoff" mentioned in the title of the published papers. A total of 131 studies showed up. Appropriate studies were shortlisted and included $(n=72)$. Cross-references if relevant were considered from the selected studies. Eligible articles were fully read by the authors and the results were compiled.

Results: The prolonged and excessive use of alcohol may lead to structural and functional brain damage, leading to ARD. The cognitive deficits are most frequently observed in domains of visuospatial functions, memory and executive tasks, with a potential of partial recovery if abstinence is maintained. However, there are doubts regarding the etiopathogenesis, nosological status, prevalence and diagnostic criteria for ARD, due to difficulty in assessment and various confounding factors.

Conclusions: With growing cohort of young and middle-aged people, there is a probable risk of upsurge of ARD. Presently, there are dilemmas over the diagnosis of independent ARD. Thus, there is a need to develop evidence-based guidelines for diagnosis and management of ARD through further systematic studies.
\end{abstract}

Keywords: Alcohols, Dementia, Cognition, Wernicke Encephalopathy, Thiamine

\section{Context}

Alcohol is considered a social evil worldwide owing to its vast array of associated problems and complications, which may manifest in medical, legal or social domains (1). Excessive and prolonged alcohol use may lead to permanent structural and functional damage to the brain (2).

Alcohol-related dementia (ARD) has received little recognition as a distinctive clinical entity, predominantly due to doubts regarding the etiopathogenesis and lack of pathophysiological profile typical for ARD. Recently, researchers have showed interest owing to its magnitude, ageing of population and focus of health bodies on alcohol-related issues across the world (3). There are doubts and debates concerning ARD whether the cognitive impairment or dementia is due to direct ethanol neurotoxicity, or representation of another underlying pathology (thiamine adeficiency) or if it is multifactorial (neurotox- icity as well as multivitamin deficiency) (4).

The correlation between the amount and duration of alcohol consumption and occurrence of ARD is not wellestablished. This is due to different types and strengths of liquor available across the countries, varying definitions of leisure drinking and pathological drinking, different cultural beliefs, and different definitions of standard drink (5). Varying patterns of drinking (duration, quantity, binge, abstinent and withdrawal periods in between) along with difficulties in obtaining an accurate self-report of alcohol use (recall problems) may complicate attempts of correlating alcohol abuse to cognitive impairment.

Various confounding factors often complicate the assessment of ARD. These may be the lifestyles of alcohol abusers, concomitant other substance abuse, associated complications like head injury, psychiatric comorbidities, and a higher rate of vascular risk factors, which may in- 
dependently predispose an individual for cognitive decline (6). There also is a great heterogeneity in the terms that describe ARD across different countries. Other terms that have been used are 'alcohol-related brain damage', 'alcohol-related brain injury' and 'alcoholic amnesia syndrome' (7).

Considering these controversies surrounding the concept of ARD, we have tried to review the nosology, prevalence, presentation, underlying pathology and management of ARD in this paper.

\section{Evidence Acquisition}

We did computerized searches to find published articles on dementia or cognitive impairment related to alcohol. Articles were retrieved by searching PubMed database for terms "alcohol and dementia”, "alcohol and cognitive impairment", and "alcohol and wernicke-korsakoff" mentioned in the title of the published papers. The search revealed 73, 50 and 8 articles, respectively for each of the search terms mentioned above. Original or review articles in English till 2014 were considered for review. Articles without abstracts $(n=23)$, case reports $(n=11)$, and animal studies $(n=12)$ were excluded. Thus, a total of 85 articles were selected for further reading after exclusion.

After reading the abstract of these articles, only those discussing dementia and cognitive impairment, primarily due to alcohol were considered $(n=72)$. The full text of the shortlisted articles were retrieved and read in full by the authors. Cross-references from selected studies were searched and further relevant articles were considered for inclusion. Data were analyzed and the relevant findings discussed below.

\section{Results}

\subsection{Nosology}

The present diagnostic criteria for alcohol-related cognitive impairment focus only on alcohol amnesic syndrome and ARD (8). The two primary classification guidelines, the International Classification of Diseases, ICD-10 (9) and the Diagnostic and Statistical Manual of Mental Disorders, DSM-5 (10) also differ in description of ARD. ICD-10 has two main classificatory diagnoses. Amnesic syndrome, according to ICD-10 (F10.6) is characterized by impairment of both recent and remote memory, with preservation of immediate recall. It also includes the Korsakov's syndrome. F10.73 of ICD-10 classifies "residual and late-onset psychotic disorder", characterized by changes of cognition and personality, induced by psychoactive substance, with subtype dementia. However, the term ARD is not mentioned and specified.

The DSM-5 has included a specifier of substance use in the diagnostic criteria for major/mild neurocognitive disorders (the term that has replaced dementia in DSM-5). Major/mild neurocognitive disorders supersede the diagnosis of alcohol-induced persisting dementia and alcohol-induced amnestic disorder, although these terms still are in use. Many clinicians prefer this term to ARD because it represents the heterogeneity of clinical features more appropriately, the stigma associated with the term dementia and alcohol gets avoided, and ARD's non-progressive nature gets distinguished from other degenerative disorders.

The Diagnostic and Statistical Manual of Mental Disorders, 4th edition (DSM-IV) included a category for 'alcoholinduced persisting dementia'. It was characterized by neurocognitive decline associated with alcohol use, in the absence of other causes of dementia (11). The WernickeKorsakoff syndrome (WKS) is described in the DSM-IV under 'alcohol-induced persisting amnestic disorder'.

Oslin refined the diagnostic criteria for ARD by including duration and severity of alcohol consumption and a minimum abstinence time, for a 'probable' diagnosis of ARD to be considered. He expected this classification would bring more clarity and stimulate further research in this area (12). Even till now, only a few studies have adopted these criteria and they still need research for being conclusive (13-15).

It can be concluded that presently, clinical judgment guides the current diagnostic criteria for ARD. Very few scientific and validated guidelines are available. Diagnosing dementia to be causally related to alcohol use remains a challenge. This has prognostic significance as ARD is considered less progressive than other forms of dementias (7).

\subsection{Epidemiology}

Presently, most of the cases of dementia are attributed to Alzheimer's disease, vascular causes and Lewy body dementia. Alcohol-related dementia is largely overlooked or seen as a comorbid factor (7). The incidence and prevalence of ARD varies across studies as there are no defined diagnostic criteria. Variations may also be due to the differences in the socio-demography of study samples. Epidemiological studies have tried to relate patterns of alcohol consumption and dementia. A review indicated a high prevalence of alcohol abuse in dementia patients ( $9 \%$ to $22 \%$ ) and $10 \%-24 \%$ prevalence of dementia in alcohol abusers (16).

It is interesting to note that the prevalence data of ARD is from the cohort that consists mainly of today's younger and middle-aged generation. Thus, it might be predicted that ARD rates would be even higher in the future, given that chronic alcohol misuse will continue. Also, ARD has a 
younger age of onset. Hence, it becomes important for the studies to include those less than 60 years of age (16). An English epidemiological study of younger-onset dementia (onset before 65 years) found 10\% rates of ARD (17). An Australian analysis demonstrated that ARD was found in 1.4\% of all patients with diagnosed dementia but its prevalence was $22 \%$ in cases who had onset before 65 years (18). A study found a direct association between cognitive decline, and chronicity and severity of alcohol use (19). Prevalence rates of ARD in hospitals and clinics have been reported to account for $10 \%$ to $24 \%$ of all dementias subtypes $(16,20)$. Reports from neurology and memory clinics suggest lower rates of ARD in dementia cases, around 3\% - 5\%, indicating less referral to these centers $(21,22)$. Older studies have suggested that of all cases of dementia, ARD accounts to approximately $10 \%$ (23). In a review by Smith, heavy use of alcohol was a contributory factor in approximately $24 \%$ cases of dementia (24).

An ongoing controversy concerns the amount of alcohol that predisposes an individual for development of ARD. United Kingdom's department of health limits daily alcohol consumption to 2 - 3 units for women and 3 - 4 units for men. A number of studies have found a J-shaped or a U-shaped relationship between the amount and consequences of alcohol use on cognitive impairment. Lightto moderate alcohol consumption is associated with a lower risk of dementia (25) while heavy drinking is associated with a higher risk (26). A meta-analysis found that small amounts of alcohol may protect against Alzheimer's dementia (27) while others suggest that it is protective against all forms (28). However, a recent study concluded that even heavy regular drinking is not a direct cause of cognitive impairment in later life (29). Studies have shown that ARD patients are mostly males, unmarried, have comorbid mental and physical conditions, likely to be identified through hospital admissions, are socially isolated, and do not have social support $(14,30)$.

The Wernicke-Korsakoff syndrome is even less well studied. The prevalence rate estimates from post-mortem studies are $1 \%-2 \%$ of the general population and $10 \%$ of alcohol consumers $(31,32)$. Varying figures are available across different nations. Netherlands had a prevalence of 48 per 100,000 (33), while incidence rates of 8 per 100,000 were estimated in Scotland in 1995 (34). A study of hospital admissions identified the Korsakoff syndrome (KS) and Wernicke's encephalopathy (WE) cases to be 0.05\% and $0.03 \%$ of all admissions, respectively (18).

\subsection{Neuropathology and Neurobiology}

The evidence from neuroimaging, neuropathological reports and autopsy evaluations suggest some degree of brain pathology in individuals diagnosed with an alcohol related disorder (35). Volume shrinkage, altered glucose metabolism and perfusion along with evidence of markedly decreased neuron density are commonly reported. Frontal lobe appears to be particularly affected $(36,37)$. Computed tomography (CT) scans showed wider cerebral sulci and larger ventricles suggestive of atrophy (38). The evidence of neuro-circuit disturbances is seen in form of significant loss of white matter (most prominent in the prefrontal cortex, cerebellum and corpus callosum) on functional imaging. Neuronal loss is also noted in the superior frontal association cortex, cerebellum and hypothalamus $(2,39)$.

The severity of alcohol dependence also correlates with neuropathophysiological and neuroimaging changes. Greater cognitive impairment has been associated with multiple and repeated withdrawal due to greater neuronal damage. A study showed a greater degree of cognitive impairment in patients undergoing two or more detoxifications compared with those with one or none (40). A study found fewer structural brain changes in treatment naive patients compared to clinical patients undergoing detoxification (41). It is postulated that brain damage worsens with repeated withdrawals, which may be associated with 'kindling-effect' of worsening of withdrawal symptoms. However, whether these changes are permanent or not and whether they relate to neurotoxicity in isolation, yet remains to be established.

Alcohol-induced brain injury may be attributed to a direct neurotoxic effect of alcohol, oxidative stress, excitotoxicity, apoptosis, disruption of neurogenesis and mitochondrial damage (42). It is proposed that repeated binge drinking and withdrawal facilitates neuronal injury by glutamate-induced excitotoxicity, mediated by upregulated N-methyl-D-aspartate receptors. This leads to increased intracellular calcium, which mediates oxidative stress, along with loss of cholinergic muscarinic receptors. This alters seizure activity and may be related to alcohol withdrawal symptoms. Dose related damage has been observed in the hippocampus, hypothalamus, and cerebellum in animal studies $(43,44)$. Cholinergic neurotransmitter system (particularly in basal forebrain), implicated in attention, learning and memory also appears to be impacted.

Imaging studies of isolated cases of uncomplicated alcoholic individuals (without any nutritional deficiency, hepatic failure, brain injury) have confirmed structural abnormalities, including changes to the corpus callosum, pons, and cerebellum (45). Abstinence results in improvement in motor abilities and cognition, and is accompanied by reversal of white matter shrinkage $(45,46)$. Restoration of myelination and axonal integrity is the chief mech- 
anism thought to be behind recovery from white matter damage (46). However, if the drinking is resumed, it again becomes vulnerable to disruption.

Another important consideration for neuropathology of ARD involves WE and KS. This leads to a hypothesis that ARD is primarily due to thiamine (vitamin B1) deficiency. Alcohol directly interferes and compromises thiamine metabolism. Also, because of poor dietary nutrition, alcohol users are at a higher risk of thiamine deficiency (31). The Wernicke's encephalopathy is an acute neurological disorder, precipitated by thiamine deficiency, characterized by the clinical triad of ophthalmoplegia, ataxia and confusion. It is defined pathologically by neuronal loss and hemorrhagic lesions in the paraventricular and periaqueductal grey matter. There seems to be a relation between the severity of neurological signs and extent of the underlying pathology (47). Reports also suggest that mild structural changes can result even with subclinical thiamine deficiency. Animal models suggest similar brain changes in direct alcohol neurotoxicity and those produced by thiamine deficiency. These changes include shrinkage of frontal brain volume, loss of cells in the basal forebrain and hypofunction of hippocampal acetylcholine. Thiamine deficiency also showed lesions in the diencephalon, which were not present in direct alcohol neurotoxicity (48). However, other pure cases of thiamine deficiency (as in cases of malnutrition and absorption disorders), without chronic and excessive alcohol consumption, show a low rate of progression to KS (49). This further supports the notion that cognitive deficits seen in ARD are multifactorial.

The Wernicke's encephalopathy is likely to be the main underlying pathology in both KS and ARD. The Korsakoff syndrome is a long-term outcome of WE and includes a syndrome of profound memory impairment, which is related to additional disruption to diencephalic and hippocampal circuitry. Because of similar pathological substrates, WE and KS are commonly referred to as the WernickeKorsakoff syndrome (WKS) (2). Patients with WKS demonstrate similar but more severe lesions in form of deficits in regional brain volumes (mammillary bodies, thalamus, cerebellar hemispheres, and vermis) than alcoholic patients without WKS (47). There have been suggestions that cases of ARD are variants of the WKS due to combination of heterogeneity in presentation of the WKS along with a lack of distinct pathology for ARD (50). Other reports suggest that ARD and WKS are distinct disorders with overlapping clinical profile (24).

\subsection{Neuropsychological Presentation and Findings}

Cognitive and behavioral changes specific to alcohol use and ARD have received limited interest and investiga- tion. Alcohol can have both acute and chronic effects on cognitive functions. Acute cognitive impairment can be seen in direct intoxication which impairs most cognitive skills and in excess, may lead to respiratory depression and stupor. Long-term alcohol use may result in amnesia and difficulty in recall (43).

Differing from other types of dementias, patients with ARD are unlikely to demonstrate language impairments $(12,24)$; however, intact confrontational naming has not been shown in all studies (15). Compared to Alzheimer's dementia, the ARD group performed better on confrontational naming, category fluency, general knowledge (semantic tasks) and verbal memory $(15,51)$. However, moderate alcohol drinking was shown to reduce likelihood of verbal memory impairment in one study (52).

In comparison with healthy controls, the ARD groups performed poorly on visuo-spatial measures, including copying tasks and clock drawing. Deficits on executive functions (verbal abstract reasoning and letter fluency), working memory and motor speed have also been observed $(15,51)$. Though smaller in their sample size, few studies have proposed that the clinical profile of ARD reflects both cortical and subcortical pathology (52). Recent single photon emission CT study supported above findings by reporting hypometabolism in the frontal cortices, thalami and basal ganglia in ARD cases (13).

Extensive investigations have been done on neuropsychology of WKS. Bowden et al. remarked that it would be more apt to describe the chronic phase of WKS as 'dementia-like deterioration'/ARD rather than severe and selective amnesia (53). Having comparatively spared implicit and procedural memories, patients typically have profound antegrade amnesia and impaired recall, with recall being better for more remote events $(54,55)$. In around $80 \%$ of the patients suffering from KS/ARD, executive deficits have been identified, mostly in the tasks assessing planning, higher-order organization, and cognitive flexibility $(56,57)$.

The Wernicke-Korsakoff syndrome and early phase of ARD are fluctuating and dynamic in their cognitive manifestations. There are evidences for variability in intellectual functions in WKS (58). Unlike other dementias, ARD has shown recovery after abstinence, even within a week, though further recovery of cognitive abilities can continue over several years (42). This correlates with current neuroimaging evidence of at least partial structural and functional recovery from alcohol-related brain damage if abstinence is maintained. According to an animal study, the effects of thiamine deficiency (increased perseverative behavior and spatial memory impairment) are more persistent as compared to the effects of persistent ethanol exposure (59). Executive function, working memory, percep- 
tual and motor impairments commonly endure following short-term abstinence, probably a reflection of compromised fronto-cortico-cerebellar functional networks (36).

The outcome and recovery rate of alcohol-related cognitive decline can be influenced by many factors like age, gender, education, chronicity, pattern of use, nutritional status and genetics. Chronicity and severity of alcohol use has been highlighted to be associated with worsening of cognitive performance, and determines the rate and the extent of cognitive recovery (46). Cognitive impairment appears to be linked to the amount of recent use and duration of abstinence rather than lifetime alcohol consumption. Binge drinking and multiple withdrawals may significantly exacerbate cognitive deficits $(60,61)$. Greater cognitive impairment is seen in chronic and older drinkers and they are less likely to recover even after abstinence (42). Lower literacy level is associated with poor recovery over time, while females appear to be more prone to develop cognitive impairment despite lower intake $(42,61)$. Family history of alcohol dependence may predispose to development of alcohol-related cognitive dysfunction, with impairment potentially predating alcohol misuse (42).

The cognitive impairment in ARD is relatively nonprogressive or even partially reversible in abstinent exdrinkers (62). Different follow-up studies have demonstrated stabilization of cognitive and functional status in some domains for the ARD group, as opposed to other forms of dementia $(14,63)$. Abstinence of up to a year may show improvement in attention, working memory, problem solving and visuo-spatial functioning along with increased brain volume. However, impairments in areas of learning and short-term memory are more persistent (64).

\subsection{Diagnosis and Management of Alcohol-Related Dementia}

Assessment and diagnosis of ARD and WKS requires high index of suspicion in a patient who has a history of long duration or heavy consumption of alcohol. A brief summary of assessment and investigations are highlighted in Table 1.

Due to varied types of presentation and no specific brain pathology, making a diagnosis of ARD becomes difficult. The Diagnostic and Statistical Manual of Mental Disorders may be helpful in diagnosing dementia due to use of alcohol. It requires the presence of memory impairment and (inability to recall or to learn new information) along with cognitive disturbances in form of either aphasia, apraxia, agnosia or/and executive dysfunctioning (11).

If ARD is detected early enough, the effects may be reversed by abstinence. Also, a healthy diet is essential to replace the deficient vitamins/minerals. Faster recovery is usually seen in females than males. Support of family and friends is paramount in achieving abstinence. Although abstinence usually results in improvement in cognitive functions, it is achieved only after a long period, extending up to several months. A recent meta-analysis showed that cognitive profile tends to become normal only after 1 year of abstinence, while certain residual cognitive impairments may persist. Different domains of cognition may improve over time, not necessarily together and to same degree. For example, the presence of visuospatial function deficits may be observed after several years of abstinence, which may be related to the decreased volume of the right parietal cortex (70). Parenteral thiamine should be administered immediately if any evidence of alcoholrelated cognitive decline is present (31). The Wernicke's encephalopathy and WKS may be reversed if diagnosed early (48 - 72 hours of the onset of symptoms) and adequately treated with parenteral thiamine (71). Failure to administer adequate doses of thiamine may result in mortality in up to $20 \%$ of WE (66), or progression to Korsakoff syndrome and ARD later on (72). Oral thiamine does not achieve an adequate plasma concentration, hence is ineffective. Other vitamin and electrolyte deficiencies should also be corrected, especially magnesium and niacin.

Due to the damage caused by alcohol metabolism coupled with thiamine deficiency, adequate thiamine transport is affected at various sites including the blood-brain barrier. As the apoenzymes are also altered, they require higher concentrations of thiamine to work normally. Thus a greater concentration of thiamine is required in the brain which the body is unable to achieve through oral supplementation. Hence, intravenous thiamine administration of up to $1 \mathrm{~g}$ may be required in the first 24 hours for successful treatment of alcohol-related thiamine deficiency (73).

According to Cochrane reviews, enough evidence is not available to guide the clinician on thiamine supplementation for prophylaxis or treatment of WE and ARD as to what dose should be given, for how long, through which route (74). EFNS European federation of the neurological societies recommendation for suspected cases of WE and WKS is $200 \mathrm{mg}$ of thiamine thrice daily, preferably intravenously (32). Until further studies are available, the following recommendations are based on available literature, to determine doses for thiamine supplementation in the prevention and treatment of WE/WKS (75). Patients with a definitive diagnosis should receive 200 - $500 \mathrm{mg}$ intravenous thiamine thrice a day for 5 - 7 days. Patients with suspected/high risk cases should be given prophylactic treatment with 100 - $200 \mathrm{mg}$ intravenous thiamine thrice a day for 3 - 5 days. In both the cases, it should be followed by oral thiamine in doses of $100 \mathrm{mg}$ thrice a day for $1-2$ weeks, then $100 \mathrm{mg}$ daily thereafter. Intramuscular route may be used if intravenous administration is not possible. 
Table 1. Assessment of Alcohol-Related Dementia

\begin{tabular}{|c|c|}
\hline Index & Description \\
\hline High Index of Suspicion & In confused patients with alcohol use/disorders and/or dietary deficiency/malnourishment and comorbid medical illness. \\
\hline Thorough history taking & $\begin{array}{l}\text { Specially noting the quantity, frequency, pattern, duration of alcohol use, and time of last use; attempts at abstinence, number of } \\
\text { detoxification attempts and severity of withdrawal symptoms. Detailed history of amnesia, apraxia, visuo-spatial deficits, aphasia } \\
\text { and difficulty in daily functioning, and its temporal relationship with alcohol use. }\end{array}$ \\
\hline Detailed clinical examination & $\begin{array}{l}\text { Eliciting dietary deficiency/malnourishment; Oculomotor abnormalities-nystagmus, ophthalmoplegia, diplopia, miosis, } \\
\text { anisocoria, papilloedema and retinal hemorrhages; Cerebellar dysfunction (ataxia, nystagmus); Mild memory impairment or } \\
\text { delirium; Autonomic disturbances like tachycardia, hypotension, hypo or hyperthermia. Other features like seizures, hearing loss, } \\
\text { spastic paraparesis or acute psychosis }(32,65,66) \text {. }\end{array}$ \\
\hline Investigations & $\begin{array}{l}\text { Complete blood counts; electrolytes; liver function tests; renal function tests; thyroid function tests; blood sugar level; coagulation } \\
\text { profile; serum levels of folate, B12, magnesium, calcium and phosphate. Raised gamma glutamyl transferase and macrocytosis are } \\
\text { useful biological markers of alcohol consumption. Magnetic resonance imaging of brain may support Wernicke encephalopathy's } \\
\text { diagnosis }(32,65) \text {. Treatment with thiamine should be started immediately without waiting for the results. Thiamine } \\
\text { pyrophosphate levels and erythrocyte transketolase activity may be helpful }(67) \text {. }\end{array}$ \\
\hline Neuropsychological testing & $\begin{array}{l}\text { Determines the degree of cognitive impairment. Folstein Mini-Mental Status Examination (MMSE) is the minimum screen for } \\
\text { dementia. The Montreal Cognitive Assessment (MoCA) Test appears to be the most appropriate screening test for detection of } \\
\text { cognitive impairments in these patients (68), as it is more sensitive than MMSE for mild-to-moderate cognitive impairments. } \\
\text { Detailed assessment of cognitive impairments may be performed by a clinical neuropsychologist. A number of test batteries may } \\
\text { be used for different domains such as memory (e.g., California Verbal Learning test), working memory (Digit Span and } \\
\text { Letter-Number Sequencing test), executive functions (e.g., Trail Making Test part B and Wisconsin Card Sorting Test, the Stroop Color } \\
\text { Word test, and the Letter Fluency Test) and processing speed (Digit Symbol-Coding)(69). }\end{array}$ \\
\hline
\end{tabular}

Every patient with alcohol dependence should be advised to strive for total abstinence. Lifestyle changes in form of exercise and healthy diet is also important. In cases with cognitive impairment, memory training techniques along with social support is required.

\subsection{Role of Memantine and Rivastigmine in Alcohol-Related De- mentia}

Memantine, a low-affinity NMDA receptor antagonist has also shown promise in improving cognition in ARD, although these findings need to be replicated. A 12-week study on patients with probable ARD showed significant improvements on global cognition, quality of life and behavioral symptoms (76). Another memantine trial on WKS patients also showed improvement in cognition (word list recall, word list recognition, time orientation, drawing an interlocking pentagon and the total Mini Mental State Examination - Korean version) of all the patients (77). A study reported that rivastigmine improved ARD in a dose 3-12 mg per day after two months of treatment (78).

\subsection{Role of Psycho-Social Interventions}

Not all patients with ARD and neurocognitive impairment will recover or benefit from abstinence and other measures mentioned above. Approximately 20\% of KS patients may require long-term institutionalized care. It is established that cognitive rehabilitation and neuropsychological training helps in slowing cognitive decline, and accelerates acquisition of new cognitive capabilities (79).
The same applies to alcohol-related neurocognitive impairment. Cognitive behavioral technique (CBT) is an important component for rehabilitation. However, efficacy of CBT depends upon the relative integrity of certain brain regions particularly frontocerebellar and preserved cognition (80). Thus, CBT cannot be effectively employed where cognition is severely impaired particularly memory and executive function (81-83).

Patients with cognitive impairment also face difficulties in several factors involved in management. These factors are motivation, participation in group therapy, selfefficacy and compliance with treatment. Cognitive impairment predicts poor compliance with treatment and decreased self-efficacy. Cognitive impairment also influences the degree of motivation, which is an essential prerequisite for effective management. Thus, cognitive dysfunction influences management by determining the efficacy of treatment and the prognosis. Hence, management should be individualized.

Cognitive remediation therapy based management programs have been investigated in very few studies in alcohol-dependent patients $(82,84)$ with encouraging results. Cognitive remediation program improves divided attention, alert capacities, working memory, and episodic memory along with improvement in other non-cognitive domains, especially psychological aspects (well-being, selfesteem) and craving (85). In spite of recognition, focus on cognitive strategies for enhancing cognition is surprisingly less and more studies are needed to evaluate the benefits. 


\section{Conclusions}

Considering the growing proportion of ageing population and rise in per capita alcohol consumption, future generations are expected to see a disproportionate increase in ARD and neurocognitive impairment. The nosological diagnostic criteria need revision and consistency. Presently, there are dilemmas over the diagnosis of independent ARD. Screening tests like the Michigan Alcohol Screening Test combined with neuropsychological tools such as MMSE and MoCA can help in early detection of these cases. There is a need to develop tools for assessment of alcohol-related cognitive impairment.

Patients with ARD are often hospitalized for other physical comorbidities and one should be vigilant enough to screen, identify and manage it at the same time. Internationally, the challenges of developing evidence-based guidelines for social work practice in dementia care are generating a lot of interest. The development of future practice guidelines for ARD should be modeled on a joint health and social care perspective. Legislative reforms in the use of alcohol similar to that used in the fight against tobacco are much needed. Therefore, ARD and alcohol-related neurocognitive impairment is an underrecognized problem and urgent action is needed to prevent this ever increasing epidemic.

\section{Acknowledgments}

We acknowledge the help and support of our coworkers.

\section{Footnote}

Authors' Contribution: Study concept and design: Mina Chandra, and Kuljeet Singh Anand; data acquisition and initial draft of the manuscript: Ankur Sachdeva, and Prabhoo Dayal; critical revision of the manuscript for important intellectual content: Mona Choudhary.

\section{References}

1. World Bank . 1993. World Development Report 1993: Investing in Health. New York; Oxford University Press; .

2. Harper C. The neuropathology of alcohol-related brain damage. Alcohol Alcohol. 2009;44(2):136-40. doi: 10.1093/alcalc/agn102. [PubMed: 19147798].

3. Blazer DG, Wu LT. The epidemiology of alcohol use disorders and subthreshold dependence in a middle-aged and elderly community sample. Am J Geriatr Psychiatry. 2011;19(8):685-94. doi: 10.1097/JGP.ob013e3182006a96. [PubMed: 21785289].

4. Ridley NJ, Draper B, Withall A. Alcohol-related dementia: an update of the evidence. Alzheimers Res Ther. 2013;5(1):3. doi: 10.1186/alzrt157. [PubMed: 23347747].
5. Turner C. How much alcohol is in a 'standard drink'? An analysis of 125 studies. Br J Addict. 1990;85(9):1171-5. [PubMed: 2224197].

6. Gupta S, Warner J. Alcohol-related dementia: a 21st-century silent epidemic?. $\mathrm{Br} J$ Psychiatry. 2008;193(5):351-3. doi: 10.1192/bjp.bp.108.051425. [PubMed:18978310].

7. Jauhar S, Smith ID. Alcohol-related brain damage: not a silent epidemic. Br J Psychiatry. 2009;194(3):287-8. doi: 10.1192/bjp.194.3.287b. [PubMed: 19252162].

8. Moriyama Y, Mimura M, Kato M, Kashima H. Primary alcoholic dementia and alcohol-related dementia. Psychogeriatrics. 2006;6(3):1148. doi: 10.1111/j.1479-8301.2006.00168.x.

9. World Health Organization . 1993. The ICD-10 classification of mental and behavioral disorders diagnostic criteria for research. Geneva; World Health Organization; .

10. American Psychiatric Association . 2013. Diagnostic and Statistical Manual of Mental Disorders (DSM-5).Arlington; American Psychiatric Association; .

11. American Psychiatric Association . 1994. Diagnostic and Statistical Manual of Mental Disorders (DSM-IV). Washington; American Psychiatric Association; .

12. Oslin D, Atkinson RM, Smith DM, Hendrie H. Alcohol related dementia: proposed clinical criteria. Int J Geriatr Psychiatry. 1998;13(4):203-12. [PubMed: 9646147].

13. Chung YA, Choi SW, Joe KH, Jeong J, Cheon Y, Kim DJ. Regional cerebral blood flow in patients with alcohol-related dementia: a SPECT study. Int J Neurosci. 2009;119(11):2100-11. [PubMed: 19863263].

14. Oslin DW, Cary MS. Alcohol-related dementia: validation of diagnostic criteria. Am J Geriatr Psychiatry. 2003;11(4):441-7. [PubMed: 12837673].

15. Schmidt KS, Gallo JL, Ferri C, Giovannetti T, Sestito N, Libon DJ, et al. The neuropsychological profile of alcohol-related dementia suggests cortical and subcortical pathology. Dement Geriatr Cogn Disord. 2005;20(5):286-91. doi: 10.1159/000088306. [PubMed: 16166775].

16. Ritchie K, Villebrun D. Epidemiology of alcohol-related dementia. Handb Clin Neurol. 2008;89:845-50. doi: 10.1016/s0072-9752(07)012730. [PubMed: 18631799].

17. Harvey RJ,Skelton-Robinson M, Rossor MN. The prevalence and causes of dementia in people under the age of 65 years. J Neurol Neurosurg Psychiatry. 2003;74(9):1206-9. [PubMed:12933919].

18. Draper B, Karmel R, Gibson D, Peut A, Anderson P. Alcohol-related cognitive impairment in New South Wales hospital patients aged 50 years and over. Aust N Z J Psychiatry. 2011;45(11):985-92. doi: 10.3109/00048674.2011.610297. [PubMed: 21961480].

19. Parsons OA. Alcohol use disorders in elderly people: fact or fiction?. Alcohol Clin Exp Res. 1998;22:945-61.

20. Carlen PL, McAndrews MP, Weiss RT, Dongier M, Hill JM, Menzano E, et al.Alcohol-related dementia in the institutionalized elderly. Alcohol Clin Exp Res. 1994;18(6):1330-4. [PubMed: 7695026].

21. Bello VM, Schultz RR. Prevalence of treatable and reversible dementias: A study in a dementia outpatient clinic. Dement Neuropsychol. Dement Neuropsychol. 2011;5:44-7.

22. McMurtray A, Clark DG, Christine D, Mendez MF. Early-onset dementia: frequency and causes compared to late-onset dementia. Dement Geriatr Cogn Disord. 2006;21(2):59-64. doi: 10.1159/000089546. [PubMed: 16276111].

23. Smith JS, Kiloh LG. The investigation of dementia: results in 200 consecutive admissions. Lancet. 1981;1(8224):824-7. [PubMed: 6111682].

24. Smith DM, Atkinson RM. Alcoholism and Dementia. Substance Use Misuse. 1995;30(13-14):1843-69. doi: 10.3109/10826089509071058.

25. Ruitenberg A, van Swieten JC, Witteman JC, Mehta KM, van Duijn CM, Hofman A, et al. Alcohol consumption and risk of dementia: the Rotterdam Study. Lancet. 2002;359(9303):281-6. doi: 10.1016/S01406736(02)07493-7. [PubMed: 11830193].

26. Luchsinger JA, Tang MX, Siddiqui M, Shea S, Mayeux R. Alcohol intake and risk of dementia. J Am Geriatr Soc. 2004;52(4):540-6. doi: 10.1111/j.1532-5415.2004.52159.x. [PubMed:15066068]. 
27. Peters R, Peters J, Warner J, Beckett N, Bulpitt C. Alcohol, dementia and cognitive decline in the elderly: a systematic review. Age Ageing. 2008;37(5):505-12. doi:10.1093/ageing/afn095. [PubMed: 18487267].

28. Neafsey EJ, Collins MA. Moderate alcohol consumption and cognitive risk. Neuropsychiatr Dis Treat. 2011;7:465-84. doi: 10.2147/NDT.S23159. [PubMed: 21857787].

29. Almeida OP, Hankey GJ, Yeap BB, Golledge J, Flicker L. Alcohol consumption and cognitive impairment in older men: a mendelian randomization study. Neurology. 2014;82(12):1038-44. doi: 10.1212/WNL.0000000000000255. [PubMed: 24553426].

30. Lennane KJ. Patients with alcohol-related brain damage: Therapy and outcome. Drug Alcohol Rev. 1988;7(1):89-92. doi: $10.1080 / 09595238880000201$.

31. Sechi G, Serra A. Wernicke's encephalopathy: new clinical settings and recent advances in diagnosis and management. Lancet Neurol. 2007;6(5):442-55. doi: 10.1016/S1474-4422(07)70104-7. [PubMed: 17434099].

32. Galvin R, Brathen G, Ivashynka A, Hillbom M, Tanasescu R, Leone MA, et al. EFNS guidelines for diagnosis, therapy and prevention of Wernicke encephalopathy. Eur J Neurol. 2010;17(12):1408-18. doi: 10.1111/j.1468-1331.2010.03153.x. [PubMed: 20642790].

33. Blansjaar BA, Horjus MC, Nijhuis HG. Prevalence of the Korsakoff syndrome in The Hague, The Netherlands. Acta Psychiatr Scand. 1987;75(6):604-7. [PubMed: 3618282].

34. Ramayya A, Jauhar P. Increasing incidence of Korsakoff's psychosis in the east end of Glasgow. Alcohol Alcohol. 1997;32(3):281-5. [PubMed: 9199729].

35. Goldstein G, Shelly C. Neuropsychological investigation of brain lesion localization in alcoholism. Adv Exp Med Biol. 1980;126:731-43. [PubMed: 7405710].

36. Sullivan EV, Harding AJ, Pentney R, Dlugos C, Martin PR, Parks $\mathrm{MH}$, et al. Disruption of frontocerebellar circuitry and function in alcoholism. Alcohol Clin Exp Res. 2003;27(2):301-9. doi: 10.1097/01.ALC.0000052584.05305.98. [PubMed: 12605080].

37. Moselhy HF, Georgiou G, Kahn A. Frontal lobe changes in alcoholism: a review of the literature. Alcohol Alcohol. 2001;36(5):357-68. [PubMed: 11524299].

38. Pfefferbaum A, Rosenbloom M, Crusan K, Jernigan TL. Brain CT changes in alcoholics: effects of age and alcohol consumption. Alcohol Clin Exp Res. 1988;12(1):81-7. [PubMed: 3279864].

39. Harper C, Matsumoto I. Ethanol and brain damage. Curr Opin Pharmacol. 2005;5(1):73-8. doi: 10.1016/j.coph.2004.06.011. [PubMed: 15661629].

40. Duka T, Townshend JM, Collier K, Stephens DN. Impairment in cognitive functions after multiple detoxifications in alcoholic inpatients. Alcohol Clin Exp Res. 2003;27(10):1563-72. doi: 10.1097/01.ALC.0000090142.11260.D7. [PubMed:14574226].

41. Fein G, Di Sclafani V, Cardenas VA, Goldmann H, Tolou-Shams M, Meyerhoff DJ. Cortical gray matter loss in treatment-naive alcohol dependent individuals. Alcohol Clin Exp Res. 2002;26(4):558-64. [PubMed: 11981133].

42. Bates ME, Bowden SC, Barry D. Neurocognitive impairment associated with alcohol use disorders: implications for treatment. Exp Clin Psychopharmacol. 2002;10(3):193-212. [PubMed: 12233981].

43. Brust JC. Ethanol and cognition: indirect effects, neurotoxicity and neuroprotection: a review. Int J Environ Res Public Health. 2010;7(4):1540-57. doi: 10.3390/ijerph7041540. [PubMed: 20617045].

44. Crews FT, Collins MA, Dlugos C, Littleton J, Wilkins L, Neafsey EJ, et al. Alcohol-induced neurodegeneration: when, where and why?.Alcohol Clin Exp Res. 2004;28(2):350-64. [PubMed: 15112943].

45. Sullivan EV, Pfefferbaum A. Neurocircuitry in alcoholism: a substrate of disruption and repair. Psychopharmacology (Berl). 2005;180(4):58394. doi: 10.1007/s00213-005-2267-6. [PubMed: 15834536].

46. Bartsch AJ, Homola G, Biller A, Smith SM, Weijers HG, Wiesbeck GA, et al. Manifestations of early brain recovery associated with abstinence from alcoholism. Brain. 2007;130(Pt 1):36-47. doi: 10.1093/brain/awl303. [PubMed: 17178742].

47. Sullivan EV, Pfefferbaum A. Neuroimaging of the Wernicke-Korsakoff syndrome. Alcohol Alcohol. 2009;44(2):155-65. doi: 10.1093/alcalc/agn103. [PubMed: 19066199].

48. Vetreno RP, Hall JM, Savage LM. Alcohol-related amnesia and dementia: animal models have revealed the contributions of different etiological factors on neuropathology, neurochemical dysfunction and cognitive impairment. Neurobiol Learn Mem. 2011;96(4):596-608. doi: 10.1016/j.nlm.2011.01.003. [PubMed: 21256970].

49. Homewood J, Bond NW. Thiamin deficiency and Korsakoff's syndrome: failure to find memory impairments following nonalcoholic Wernicke's encephalopathy. Alcohol. 1999;19(1):75-84. [PubMed: 10487391].

50. Zahr NM, Kaufman KL, Harper CG. Clinical and pathological features of alcohol-related brain damage. Nat Rev Neurol. 2011;7(5):284-94. doi: 10.1038/nrneurol.2011.42. [PubMed: 21487421].

51. Saxton J, Munro CA, Butters MA, Schramke C, McNeil MA. Alcohol, dementia, and Alzheimer's disease: comparison of neuropsycholog ical profiles. J Geriatr Psychiatry Neurol. 2000;13(3):141-9. [PubMed: 11001137].

52. Byeon H, Lee Y, Lee SY, Lee KS, Moon SY, Kim H, et al. Association of alcohol drinking with verbal and visuospatial memory impairment in older adults: Clinical Research Center for Dementia of South Korea (CREDOS) study. Int Psychogeriatr. 2015;27(3):455-61. doi: 10.1017/S104161021400146X. [PubMed: 25119654].

53. Bowden SC. In: Dementia. Ames D, Burns A, O'Brien J, editors. London: Edward Arnold; 2010. Alcohol related dementia and WernickeKorsakoff Syndrome.

54. Fama R, Marsh L, Sullivan EV. Dissociation of remote and anterograde memory impairment and neural correlates in alcoholic Korsakoff syndrome. J Int Neuropsychol Soc. 2004;10(3):427-41. doi: 10.1017/S135561770410310X. [PubMed: 15147600].

55. Kopelman MD, Thomson AD, Guerrini I, Marshall EJ. The Korsakoff syndrome: clinical aspects, psychology and treatment. Alcohol Alcohol. 2009;44(2):148-54. doi: 10.1093/alcalc/agn118. [PubMed:19151162]

56. Van Oort R, Kessels RP. Executive dysfunction in Korsakoff's syndrome: Time to revise the DSM criteria for alcohol-induced persisting amnestic disorder?. Int J Psychiatry Clin Pract. 2009;13(1):78-81. doi 10.1080/13651500802308290. [PubMed: 24946125].

57. Dirksen CL, Howard JA, Cronin-Golomb A, Oscar-Berman M. Patterns of prefrontal dysfunction in alcoholics with and without Korsakoff's syndrome, patients with Parkinson's disease, and patients with rupture and repair of the anterior communicating artery. Neuropsychiatr Dis Treat. 2006;2(3):327-39. [PubMed: 19412479]

58. Cutting J. The relationship between Korsakoff's syndrome and alcoholic dementia. BrJ Psychiatr. 1978.

59. Riberio AM, Pereira SR. In: Neuromethods. De Deyn PP, Van Dam D, editors. New York: Springer Science+Business Media; 2011. Animal models of alcohol-induced dementia.

60. Horner MD, Waid LR, Johnson DE, Latham PK, Anton RF. The relationship of cognitive functioning to amount of recent and lifetime alcohol consumption in outpatient alcoholics. Addict Behav 1999;24(3):449-53. [PubMed: 10400285].

61. Scheurich A. Neuropsychological functioning and alcohol dependence. Curr Opin Psychiatry. 2005;18(3):319-23. doi: 10.1097/01.yco.0000165602.36671.de. [PubMed:16639156].

62. Goldman MS. Cognitive impairment in chronic alcoholics. Some cause for optimism. Am Psychol. 1983;38(10):1045-54. [PubMed: 6357006].

63. Woodburn KJ, Johnstone EC. Early-onset dementia in Lothian, Scotland: an analysis of clinical features and patterns of decline. Health Bull (Edinb). 1999;57(6):384-92. [PubMed: 12811870].

64. Gazdzinski S, Durazzo TC, Meyerhoff DJ. Temporal dynamics and determinants of whole brain tissue volume changes during recovery from alcohol dependence. Drug Alcohol Depend. 2005;78(3):263-73. 
doi: 10.1016/j.drugalcdep.2004.11.004. [PubMed: 15893157].

65. Caine D, Halliday GM, Kril JJ, Harper CG. Operational criteria for the classification of chronic alcoholics: identification of Wernicke's encephalopathy. J Neurol Neurosurg Psychiatry. 1997;62(1):5160. [PubMed: 9010400].

66. Harper CG, Giles M, Finlay-Jones R. Clinical signs in the WernickeKorsakoff complex: a retrospective analysis of 131 cases diagnosed at necropsy. J Neurol Neurosurg Psychiatry. 1986;49(4):341-5. [PubMed 3701343].

67. Charness ME. Overview of the chronic neurologic complications of alcohol 2010.. Available from: www.uptodate.com.

68. Copersino ML, Fals-Stewart W, Fitzmaurice G, Schretlen DJ, Sokoloff J, Weiss RD. Rapid cognitive screening of patients with substance use disorders. Exp Clin Psychopharmacol. 2009;17(5):337-44. doi: 10.1037/a0017260. [PubMed:19803633].

69. Bernardin F, Maheut-Bosser A, Paille F. Cognitive impairments in alcohol-dependent subjects. Front Psychiatry. 2014;5:78. doi: 10.3389/fpsyt.2014.00078. [PubMed: 25076914].

70. Stavro K, Pelletier J, Potvin S. Widespread and sustained cognitive deficits in alcoholism: a meta-analysis. Addict Biol. 2013;18(2):203-13. doi: 10.1111/j.1369-1600.2011.00418.x. [PubMed: 22264351].

71. Thomson AD, Cook CC, Touquet R, Henry JA, Royal College of Physicians L. The Royal College of Physicians report on alcohol: guidelines for managing Wernicke's encephalopathy in the accident and Emergency Department. Alcohol Alcohol. 2002;37(6):513-21. [PubMed 12414541].

72. Victor M, Adams RD, Collins GH. The Wernicke-Korsakoff Syndrome: And Related Neurologic Disorders Due to Alcoholism and Malnutrition. FA Davis Company; 1989.

73. Thomson AD, Marshall EJ. The treatment of patients at risk of developing Wernicke's encephalopathy in the community. Alcohol Alcohol. 2006;41(2):159-67. doi:10.1093/alcalc/agh250. [PubMed: 16384870].

74. Day E, Bentham P, Callaghan R, Kuruvilla T, George S. Thiamine for Wernicke-Korsakoff Syndrome in people at risk from alcohol abuse. Cochrane Database Syst Rev. 2004(1):CD004033. doi 10.1002/14651858.CD004033.pub2. [PubMed: 14974055].

75. Latt N, Dore G. Thiamine in the treatment of Wernicke encephalopa- thy in patients with alcohol use disorders. Intern MedJ. 2014;44(9):9115. doi: 10.1111/imj.12522. [PubMed: 25201422].

76. Cheon Y, Park J, Joe KH, Kim DJ. The effect of 12-week openlabel memantine treatment on cognitive function improvement in patients with alcohol-related dementia. Int J Neuropsychopharmacol. 2008;11(7):971-83. doi: 10.1017/S1461145708008663. [PubMed: 18346293].

77. Rustembegovic A, Kundurovic Z, Sapcanin A, Sofic E. A placebocontrolled study of memantine (Ebixa) in dementia of WernickeKorsakoff syndrome. Med Arh. 2003;57(3):149-50. [PubMed: 12858653].

78. Djokic G, Zivkovic N. P01-28 Rivastigmine in treatment of alcohol - induced persisting dementia. Eur Psychiatr. 2009;24:S416. doi: 10.1016/s0924-9338(09)70649-2.

79. Roehrich L, Goldman MS. Experience-dependent neuropsychological recovery and the treatment of alcoholism. J Consult Clin Psychol. 1993;61(5):812-21. [PubMed: 8245278].

80. Kumari V, Peters ER, Fannon D, Antonova E, Premkumar P, Anilkumar AP, et al. Dorsolateral prefrontal cortex activity predicts responsiveness to cognitive-behavioral therapy in schizophrenia. Biol Psychiatry. 2009;66(6):594-602. doi: 10.1016/j.biopsych.2009.04.036. [PubMed: 19560121].

81. Hunt SA, Baker AL, Michie PT, Kavanagh DJ. Neurocognitive profiles of people with comorbid depression and alcohol use: implications for psychological interventions. Addict Behav. 2009;34(10):878-86. doi: 10.1016/j.addbeh.2009.03.036. [PubMed: 19398163].

82. Allen DN, Goldstein G, Seaton BE. Cognitive rehabilitation of chronic alcohol abusers. Neuropsychol Rev. 1997;7(1):21-39. [PubMed: 9243529].

83. Goldstein G, Haas GL, Shemansky WJ, Barnett B, Salmon-Cox S. Rehabilitation during alcohol detoxication in comorbid neuropsychiatric patients. J Rehabil Res Dev. 2005;42(2):225-34. [PubMed: 15944887].

84. Goldman MS. Experience-dependent neuropsychological recovery and the treatment of chronic alcoholism. Neuropsychol Rev. 1990;1(1):75-101. [PubMed: 2152526].

85. Rupp CI, Kemmler G, Kurz M, Hinterhuber H, Fleischhacker WW. Cognitive remediation therapy during treatment for alcohol dependence. J Stud Alcohol Drugs. 2012;73(4):625-34. [PubMed: 22630801]. 